\title{
Prediction of Atmospheric varibilities in North East India during Tropical Cyclones: Use of Numerical Weather Prediction Model and back propagation Artificial Neural Network (ANN)
}

\author{
S. Das, M. Devi, K. Prakash, A. K. Barbara \\ Department of Physics, Gauhati University, India \\ imsubratdas@gmail.com
}

\begin{abstract}
The precurssive atmospheric features induced in temperature, precipitation and wind by cyclones generated at Bay of Bengal (BoB), are extracted by using numerical weather prediction model VARSHA. The track of the cyclones are also projected through wind circulation pattern from the model output. Further, back propagation Artificial Neural Network (ANN) technique is adopted for identifying predictive features in temperature for translation these information in forecasting precipitation over North East India. The reliability of both approaches are discussed.
\end{abstract}

Key words: 1. VARSHA model, 2.Back propagation 3. ANN

\section{Introduction}

Weather forecasting is an applied science where a number of atmospheric parameters like temperature, pressure, humidity and wind need to be involved while framing a predictive model. It is also important to utilize these parameters effectively for understanding the regional climatic situation. The North East (NE) part of India has the special significant in this aspect because of its complex topography with three corridors of moisture-flow from (i) west (ii) south and (iii) NE directions, as displayed in Figure 1. Involving all factors into consideartion, VARSHA model is run regularly at Gauahti University to predict growth and develoepmnts of cyclons, their track and also the cyclone induced precipitation and temprature. 


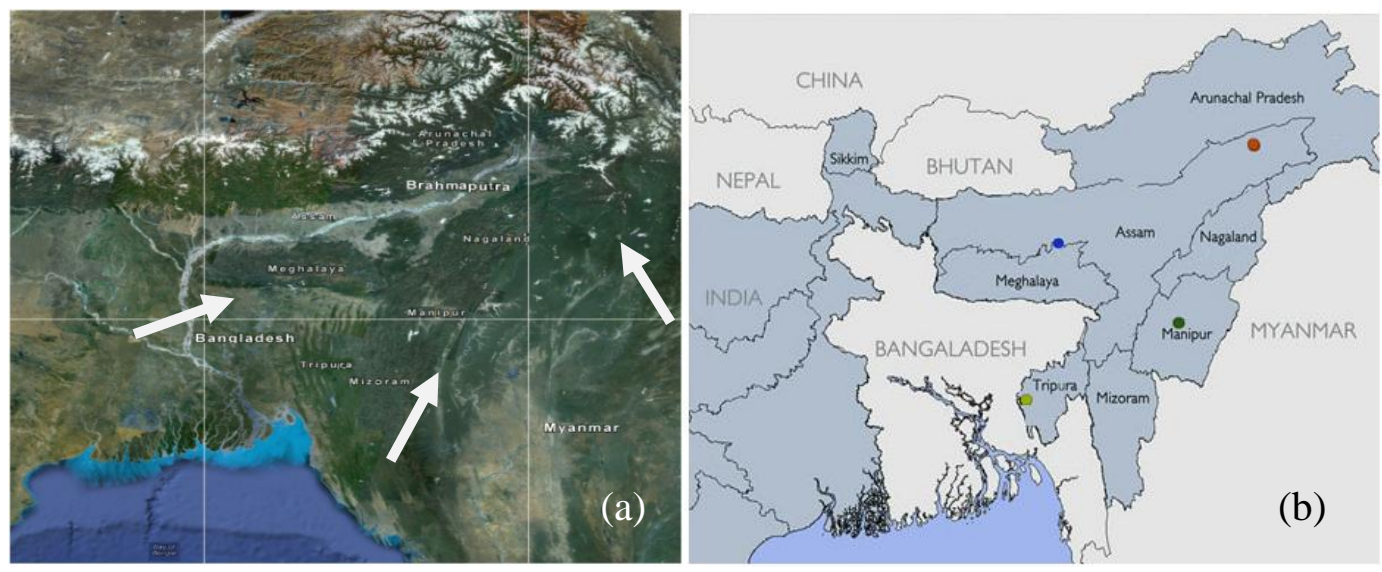

Figure 1: Presents (a) the complex topography of the NE, with three wind corridors as marked by arrows and (b) the selected sites (marked as dots) for comparing model evaluated precipitation magnitudes with observations.

Artifical Neural Network technique is further used to predict worst weather situation of this type, through training of data sets by complex mappings from inputs to outputs. In such technique, there are different types of training or learning algorithms. Back Propagation Neural Network (BPN) algorithm is one of such technique where in each iteration error is reduced. This algorithm is thus adopted here for prediction of precipiatation mainly taking temperartture as one of the prime parameters by involving relevant data sets of NE region. The paper thus aims at to utilize the VARSHA model along with Artifical Neural Network technique to study the weather (temperature as well as precipitation ) over NE region, specially during growth and development of cyclone generated at Bay of Bengal (BoB).

It is well documented that tropical cyclone originates and intensifies over warm tropical oceans. Larger sea surface and higher temperature are the pre-conditions for the development of tropical cyclones. BoB provides better conditions for the development of system. Tropical cyclones that develop mainly over warm seas may cause spree of devastations on trail when they dissipate their energy after hitting a land surface [Devi et al. 2013]. Such cyclonic flow of energy was explained through convection theory as early as in 1841 and scientists then realized the need of understanding atmospheric physics in association with meteorology with the aims of forecasting climatic status through growth and development of cyclonic storms. With the launching of balloon facilities and Radiosonde observations [1904, 1927] progressive improvements in these directions were achieved. At present a number of satellites are available dedicated to such observations. Such as the Tropical Rainfall Measuring Mission (TRMM), 
National Oceanic and Atmospheric Administration (NOAA), Climate Prediction Center's (CPC) morphing method (CMORPH) [Joyce et al. 2004; Dvorak, 1975; Englehart and Douglas 2001]. Numerical models have been adopted for understanding the life span of cyclonic storms and in a limited way in realizing their effects on precipitation and climatology [Amorocho and Wu 1977; Stumpf et al. 1995; Pu et al. 2002; Chen and Marks 2006; Lau and Zhou 2012]. Hurricane induced changes in oceanic and of meteorological parameters are also conducted by a number of workers [Gautam et al. 2005; Gautam et al. 2005]. However with all these available inputs there are needs to devlope model for prediction of cyclone induced precipitation that are dictated by regional topology, the aims of the work.

\section{Methodology}

\subsection{Numerical weather prediction model VARSHA}

Most of the atmospheric prediction models are based on a set of non linear partial differential equations which need to be solved efficiently for prediction of the future state of the atmosphere from a given initial state. Since the domain of atmospheric flow is bounded at the bottom by the surface of the earth, exchange of properties takes at this surface and this necessitates to prescribe boundary condition for various quantities. The topography also plays an important role in controlling the airflow not only close to the ground but also at upper level. All physical processes involving moisture, tempearure, turbulence, gravity wave drag, land surface processes need to be is parameterized in terms of the variable in a model.

The governing equations for this model VARSHA are based on mass, momentum, energy and moisture conservation. The momentuam equations are replaced by the velocity and divergence equations. The vertical coordinate is $\sigma=\mathrm{p} / \mathrm{p}^{*}$ where $\mathrm{p}$ is the layer pressure and $\mathrm{p}^{*}$ is the surface pressure. [U. N. Sinha et. al 1994]

The model prognostic equations are:

Law of conservation of mass:

$$
(\partial \rho / \partial \mathrm{t})+\nabla \cdot(\rho \mathrm{V})=0
$$

Here, $\rho$ is density, $\mathrm{V}$ is the velocity and $\mathrm{t}$ denotes time. The law of conservation of momentum is expressed by the following equation: 


$$
\mathrm{dV} / \mathrm{dt}+2 \Omega \times \mathrm{V}=-\nabla \mathrm{P} / \rho-\nabla \Phi+\mathrm{F}
$$

Where $\mathrm{P}$ is the pressure, $\Phi$ is the geopotential, $\Omega$ is the earth's angular velocity vector and F represents the frictional forces. The law of conservation of energy can be expressed in terms of $\theta=\mathrm{T}\left(\mathrm{P}_{0} / \mathrm{p}\right)^{\mathrm{K}}$, the potential temperature; $\kappa=R / C_{p}, C_{p}$ is the specific heat at constant pressure; $R$ the gas constant for air and temperature $\mathrm{T}$, as :

$$
\mathrm{d}(\ln \theta) / \mathrm{dt}=\mathrm{H}_{\mathrm{T}} / \mathrm{C}_{\mathrm{P}} \mathrm{T}
$$

Here $\mathrm{H}_{T}$ represents the adiabatic heating term and the equation of state is governed by $\mathrm{P}=\rho \mathrm{RT}$. Finally the moisture conservation equation is written in terms of rate of changes of specific humidity q with time

$$
\mathrm{dq} / \mathrm{dt}=\mathrm{S}
$$

Here, $\mathrm{S}$ represents sources and sinks of moisture.

Based on these basic physical and mathematical concepts, the model VARSHA is framed with grid size $80 \mathrm{~km}$ (upgraded to $40 \mathrm{~km}$ ). Thus the model acts as a mesoscale hydrostatic one and is rergularly run at at Gauhati University $\left(26^{\circ} 10^{\prime} \mathrm{N}, 91^{\circ} 45^{\prime} \mathrm{E}\right)$, at an eight-processor Flosolver machine to predict the atmospheric variabilities like specific humidity, surface pressure, temperature, wind and precipitation. The tracking of wind profiles from the model output thus can provide the track of a cyclones and this approach is adopted in this paper in path-prediction of cyclones generated at the BoB. The model outputs are further utilised in forecasting temperature, precipitation, humidity, surface pressure etc., over the North-Eastern part of India, induced by such events. The initial conditions of the model are prepared from final analysis dataset (FNL) of National Centre for Environmental Prediction (NCEP), available at $1^{\circ} \mathrm{X}$ $1^{\circ}$ resolutions. A few $\mathrm{BoB}$ generated cyclonic cases are studied and are presented individual events in the following article.

\subsubsection{Case 1: Cyclone MAHASEN}

The routine observation of VARSHA model ouput has shown that on $10^{\text {th }}$ May, 2013 a low pressure zone is developed at around latitude $5.0^{\circ} \mathrm{N}$ and longitude $92.0^{\circ} \mathrm{E}$, which becomes significant on May 11 (Figure 2). The developed system being the index of growth of a cyclone, five day predction on its track as well as precipitation over the NE, is made though this model. The wind flow pattern presented in Figure 2 of VARSHA shows that the cyclone will landfall at Mayanmar boarder on $15^{\text {th }}$ May. The 
corresponding prediction in precipitation is also shown in Figure 3 where initial condition $11^{\text {th }}$ May is taken. The TRMM observation in Figure 4 also clearly presents the prediction track moving towards the Mayanmar boarder and discipiating on $15^{\text {th }}$ May over this region. Figure 4 also shows practically no role of this cyclone on precipitation over NE Region except in Tripura and Mizoram.
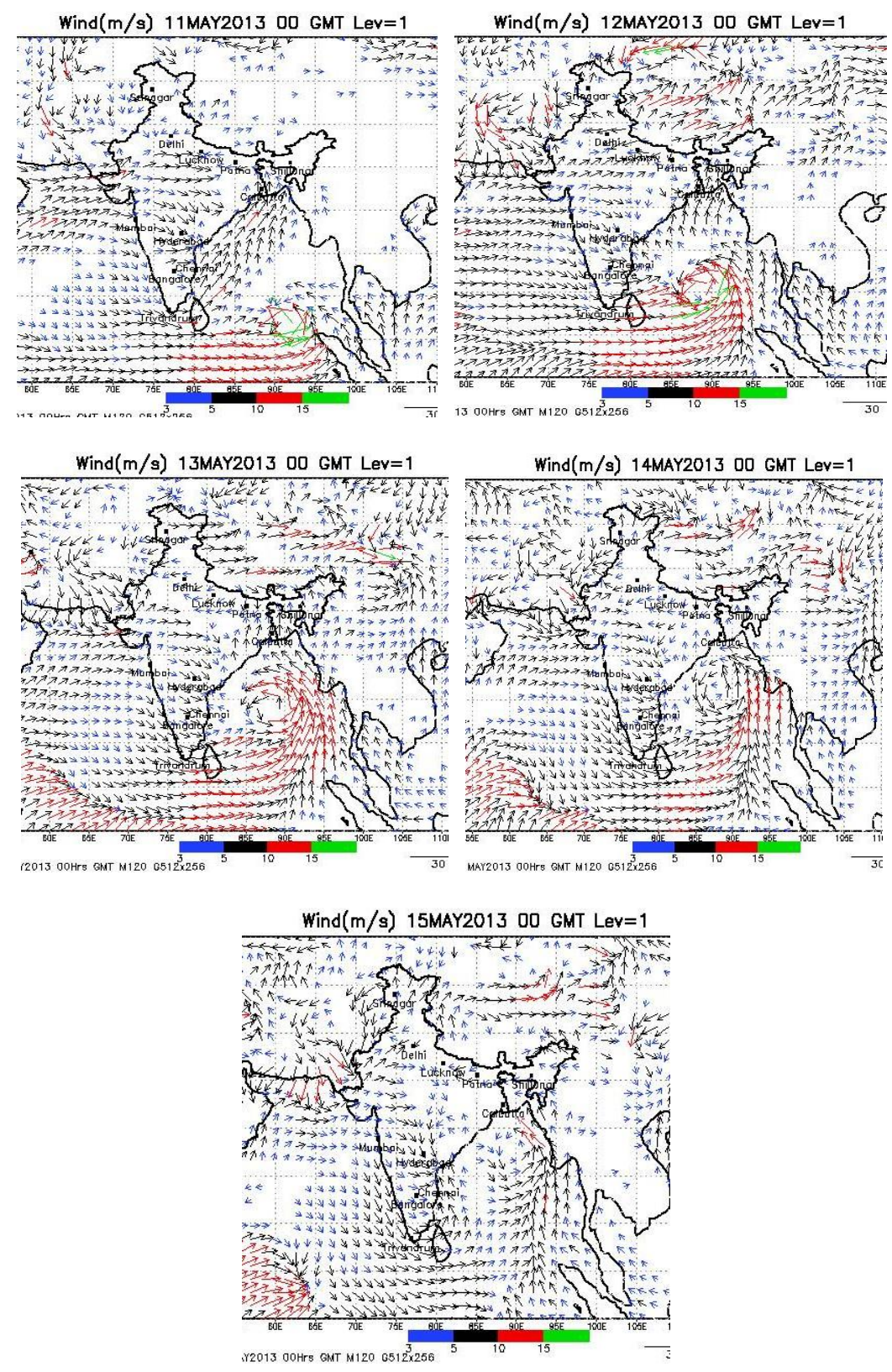

Figure 2: Prediction of wind pattern by VARSHA on Cyclone MAHASEN 
Along with the cyclonic track, the prediction of rainfall at the NE States measured by the model during this cyclonic situation is shown in Figure 3. For reliability purpose we compare this model output with TRMM observed satellite data (Figure 4). One can note the synchonisation between the model evlautaed precipitation trends with TRMM measured one.
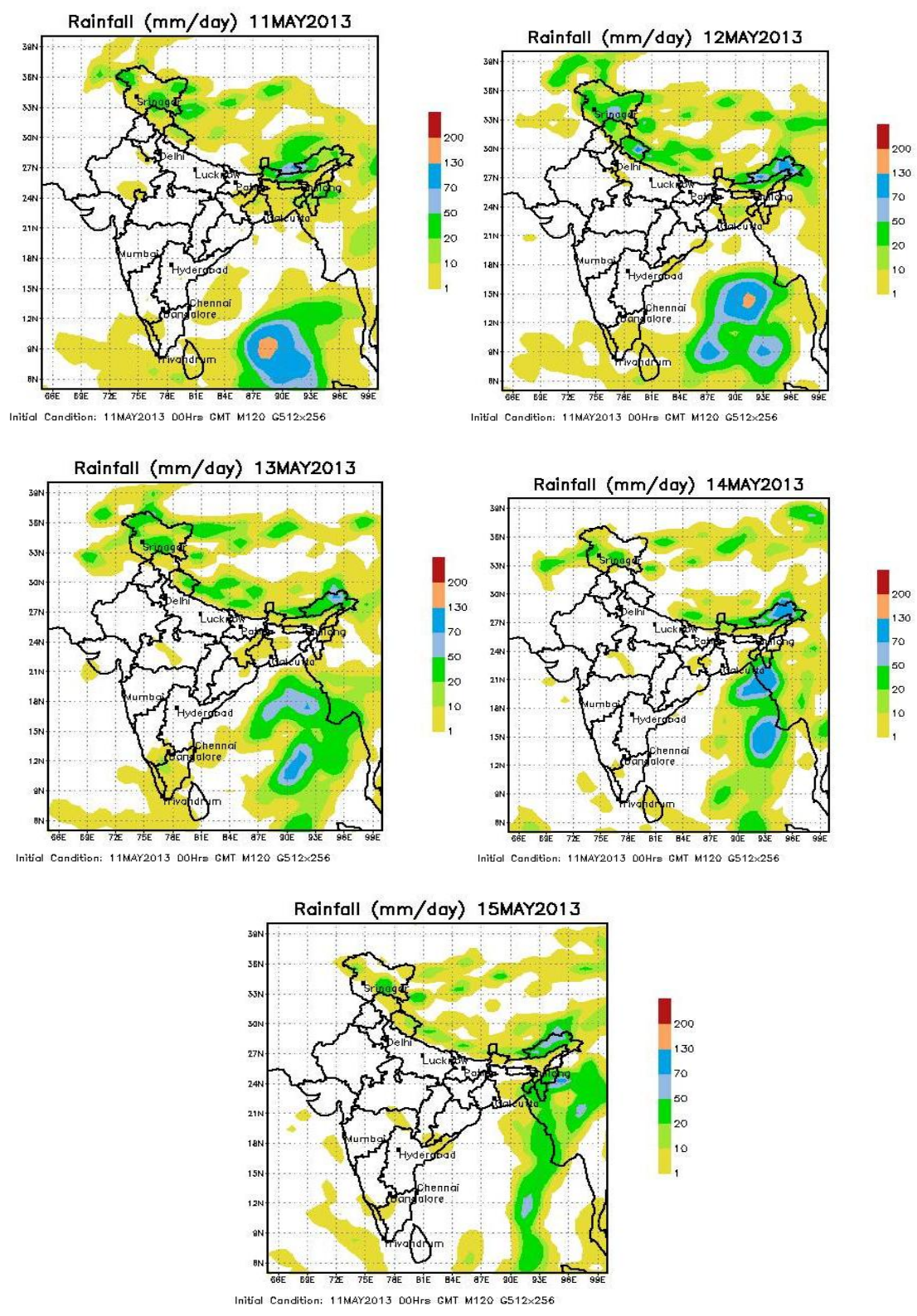

Figure 3: Precipitation trend during growth and dissipation of cyclone MAHASEN in and around NE region : VARSHA model evaluated stages 

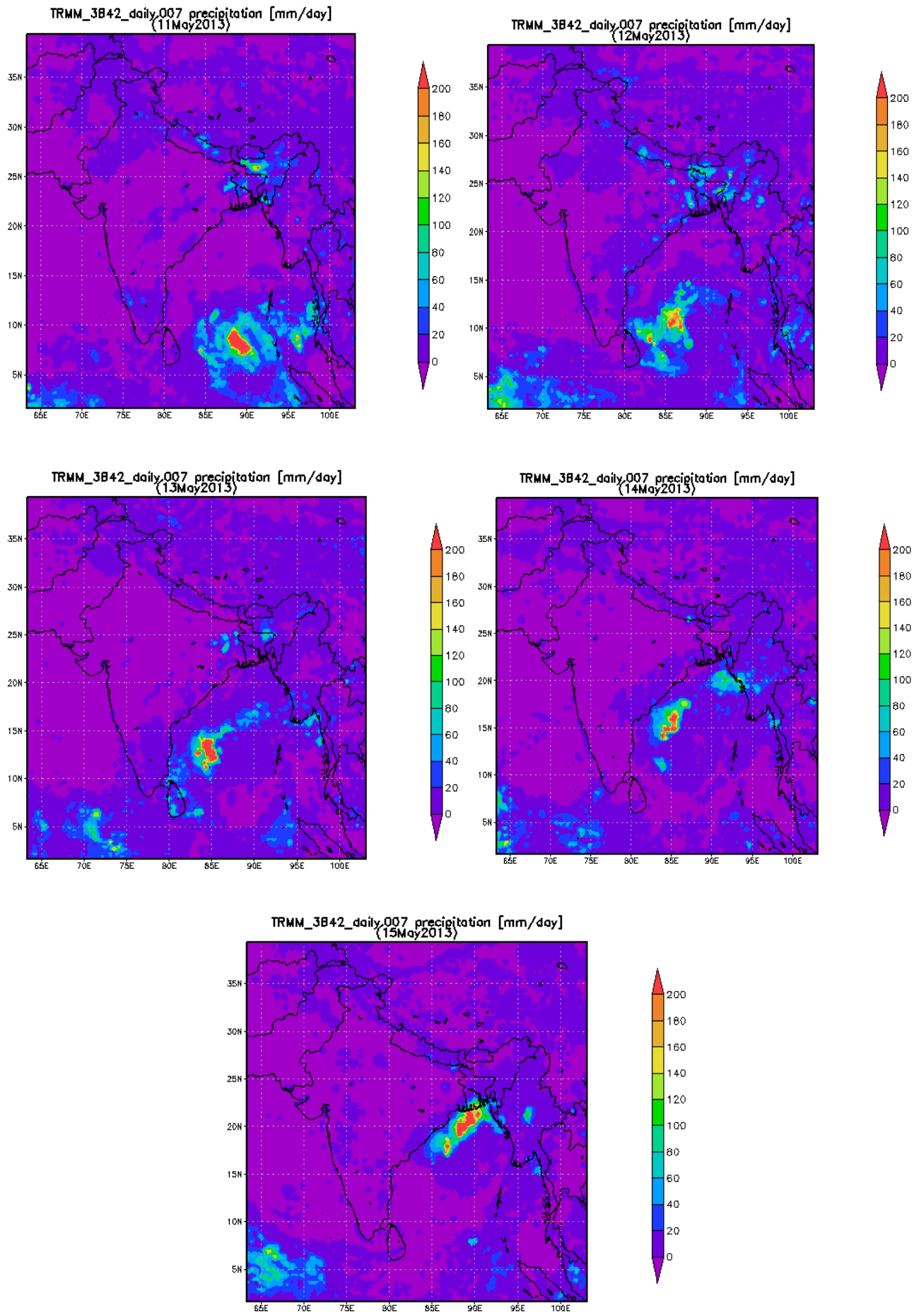

Figure 4: TRMM observation of precipitation during cyclone MAHASEN 


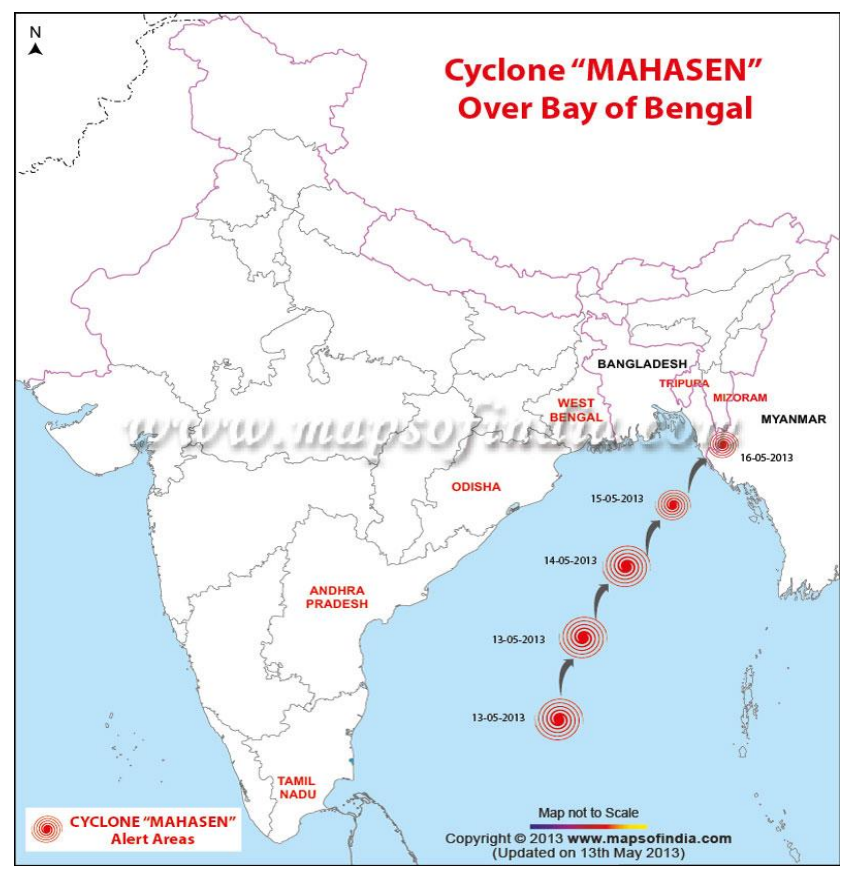

Figure 5: Observed cyclonic track of MAHASEN over BoB. (Image: www.mapsofindia.com)

\subsubsection{Comperision with the Observation:}

It has been observed that both VARSHA output and TRMM observation show no role of Mahasen cyclone precipitation in the NE region till May-13. It is also well predicted by VARSHA that around 70 $\mathrm{mm}$ /day precipitation is expected in the latitude $20^{\circ} \mathrm{N}$ in the Mayanmar region which is also well observed by TRMM on the same day i.e. on $14^{\text {th }}$ May. However on $15^{\text {th }}$ May VARSHA shows precipitation over Tripura, Mizoram and Manipur with magnitude of around 20-50 mm/day but TRMM observation donnot show significant precipitation over this region. But in absence of spot precipitation observation of this region, such conclusion will require observations from IMD at the respective location which will be our future course of study.

\subsubsection{Case II Cyclone MORA}

The routine observation from VARSHA output indicates development of a cyclonic eye at Lat $90^{\circ} \mathrm{E}$ and Lon $15^{0} \mathrm{~N}$, on $27^{\text {th }}$ May, 2017. For identifying the movement of the newly formed cyclone, the model was 
run for 5 days at initial condition $27^{\text {th }}$ May. The model evaluate output on wind profile are presented in Figure 6. It is seen that this cyclone designated as Mora started intensifying and moved towards NE direction, after formation eye started moving towards NE and fully formed on $28^{\text {th }}$ May. Finally the model predicted that the landfall will be at Lat $22^{0} \mathrm{~N}$ Lon $92^{0} \mathrm{E}$ on $30^{\text {th }}$ May. After the landfall, due to decrease in moisture content and interaction with land, the cyclone to degenerate rapidly into a deep depression. The IMD observed track on Mora cyclone shown in the Figure 7 indicate developmemt of deep depression on $28^{\text {th }}$ May, at lat $15.4^{0} \mathrm{~N}$ and lon $90^{\circ} \mathrm{E}$ is similar to that predicted by the VARSHA. The landfall area of $22^{0} \mathrm{~N}$ and $90^{\circ} \mathrm{E}$ as observed by IMD is well forcsted by the VARSHA, five days in advance.

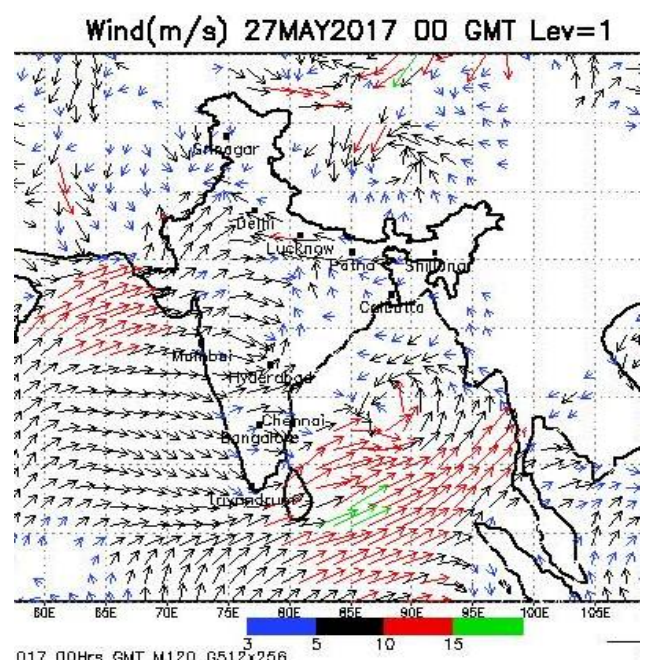

017 OOHrs GNT M120 G512 $\frac{3}{3} \times 256$

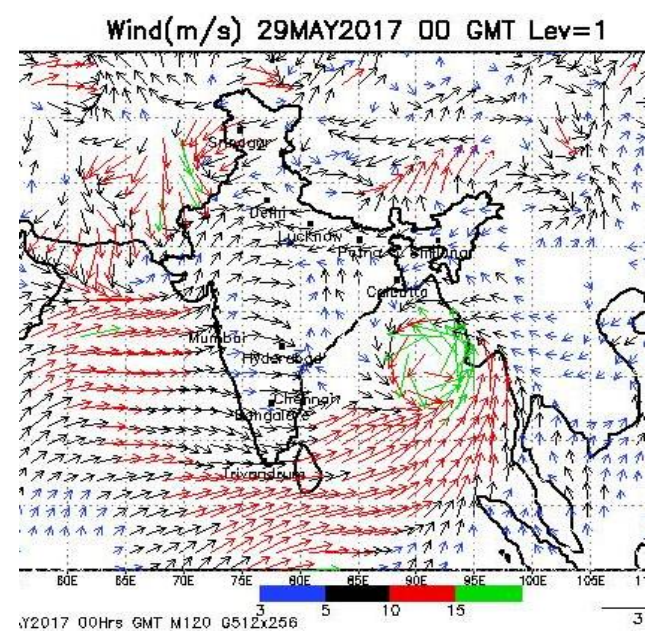

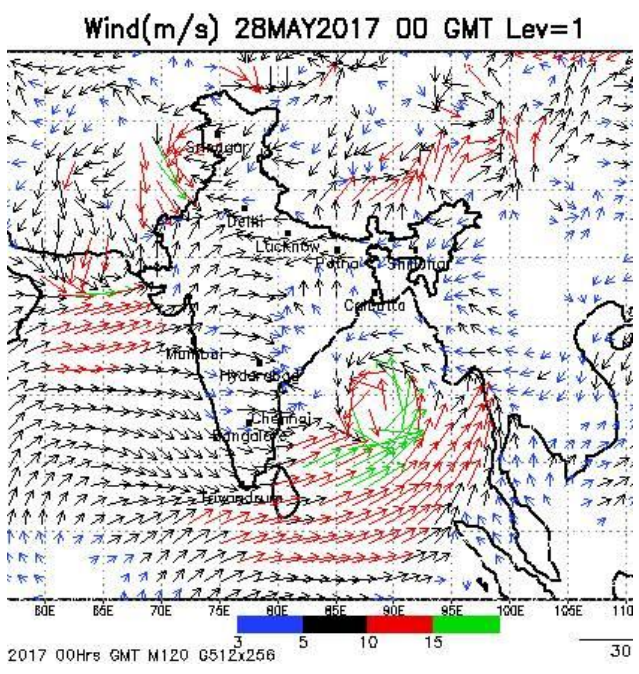

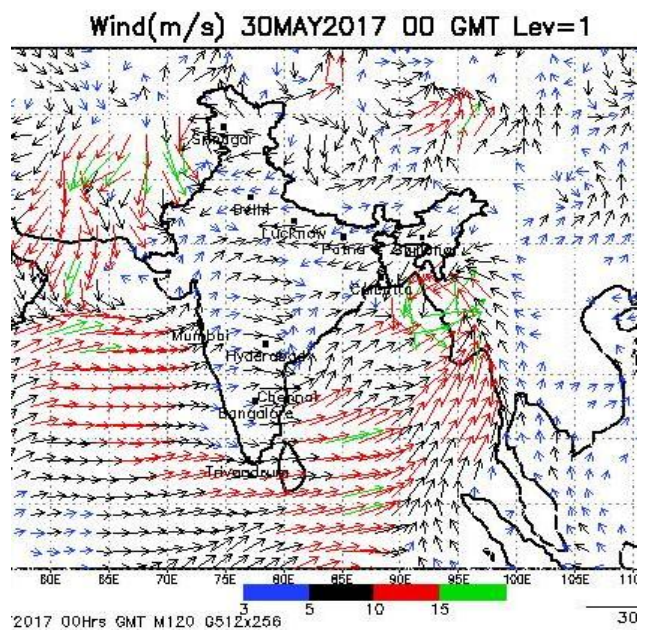

Figure 6: Prediction of wind pattern by VARSHA on Cyclone Mora 


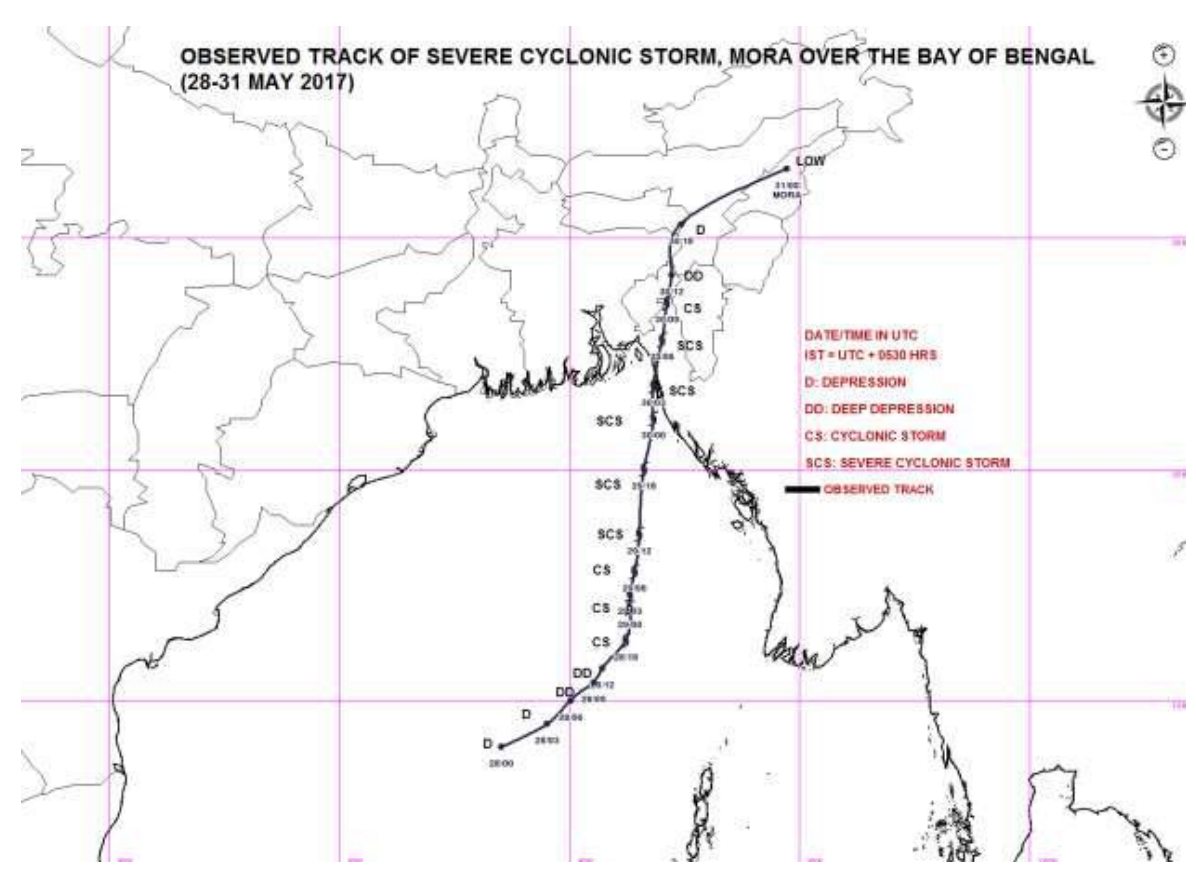

Figure 7: IMD observed track of MORA Cyclone

Next the model eavalutaed precipiataion caused by the cyclone is examined with different initial conditions to predict the intensity of rainfall at Assam, Meghalaya, Tripura, Mizoram, Manipur, Nagaland. The precipitation patterns so obtained are mapped with special reference to NE region as shown in Figure 8. The heavy precipitation zones with rainfall greater than $150 \mathrm{~mm} /$ day are predicted by the VARSHA to shift from the location $15^{\circ} \mathrm{N}, 90^{\circ} \mathrm{E}$ on May $28^{\text {th }}$ to $30^{0} \mathrm{~N}, 96^{0} \mathrm{E}$ on the day of landfall (May 30). The observation from TRMM shows the intensity of precipitation from the growth to landfall of the cycole and till it dissipated. The TRMM observed precipitation induced by Mora cyclone also displays a shift of heavy precipating zone from the almost same location as predicted by VARSHA. The magnitude of precipitation predicted by VARSHA and also the covered area are well syncrhonised with the TRMM satellite observed precipitation during the cyclonic situation. From the comparision it can be well adopted that VRASHA prediction of precipitation five days prior to the cyclone is reliable for the NE region of India. 

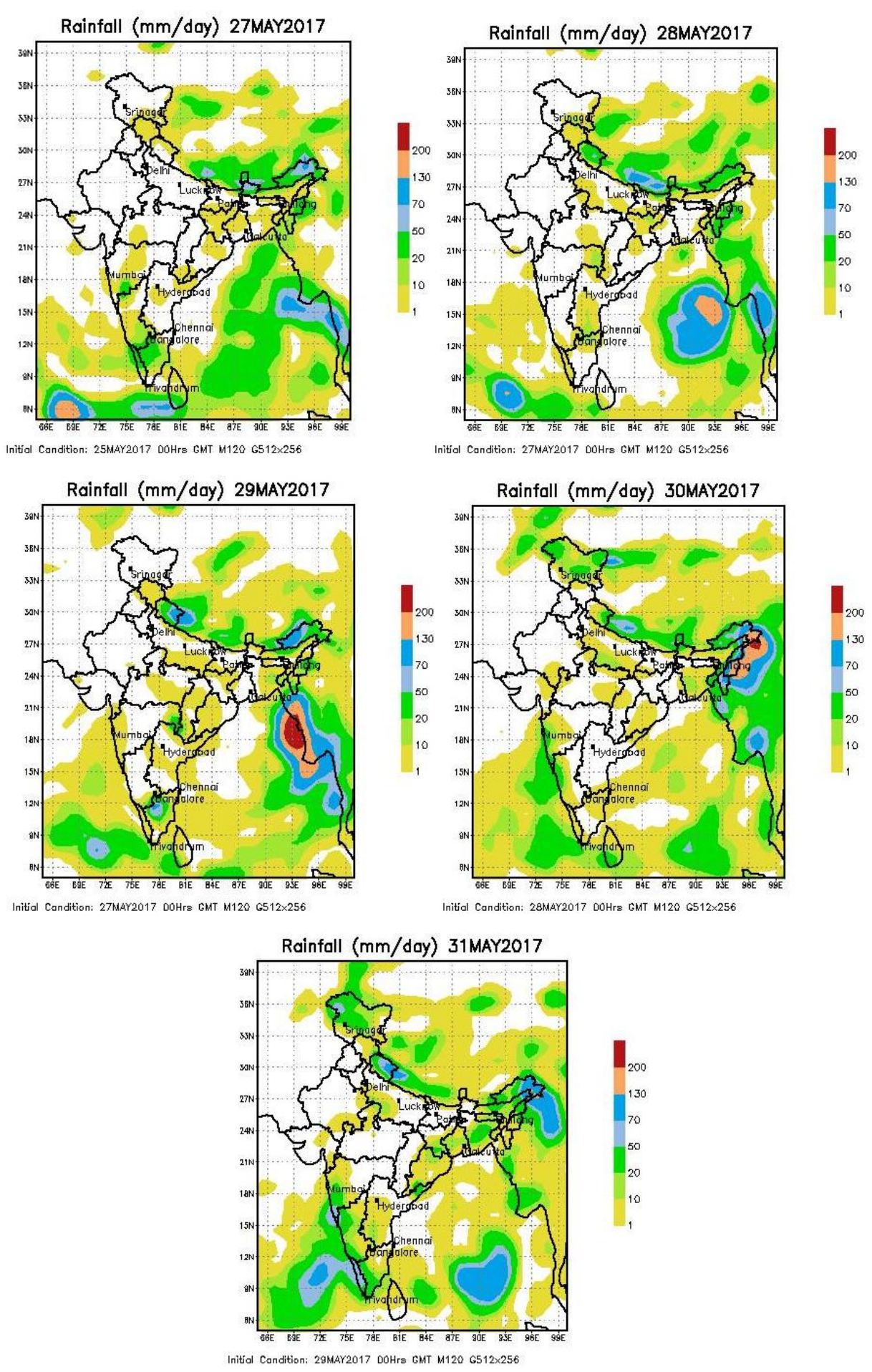

Figure 8: Precipitation trend during cyclone Mora in and around NE region : VARSHA model evaluated stages 
International Journal of Electronics and Applied Research (IJEAR) vol. 4, issue 2, Dec 2017 Online (http://eses.net.in/ESES Journal)

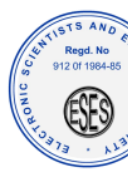

TRMM 27-05-2017

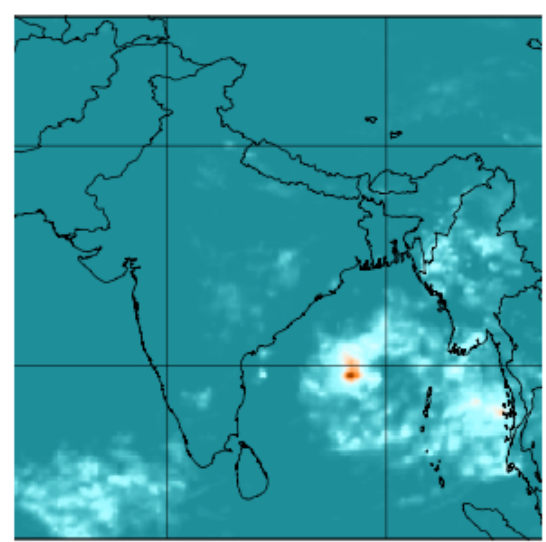

TRMM 29-05-2017

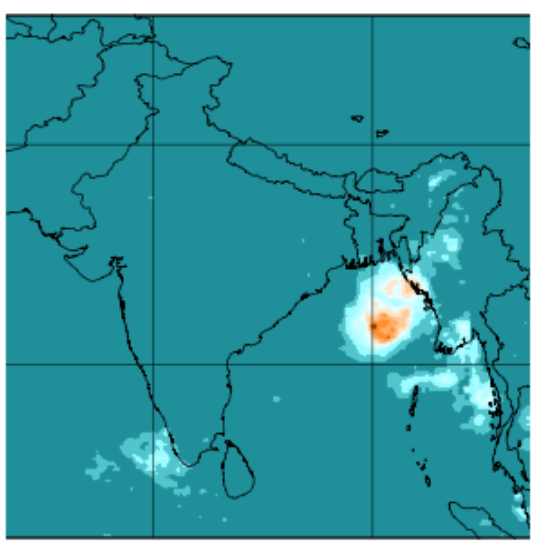

TRMM 28-05-2017

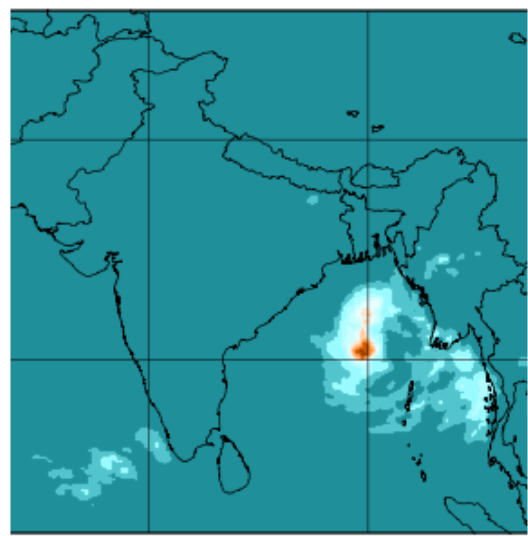

TRMM 30-05-2017

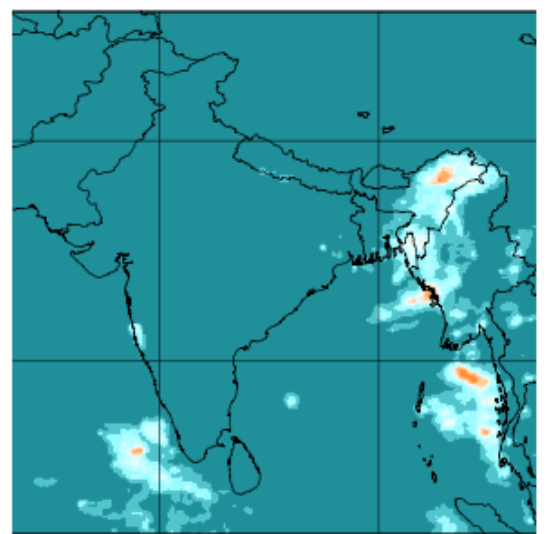

TRMM 31-05-2017

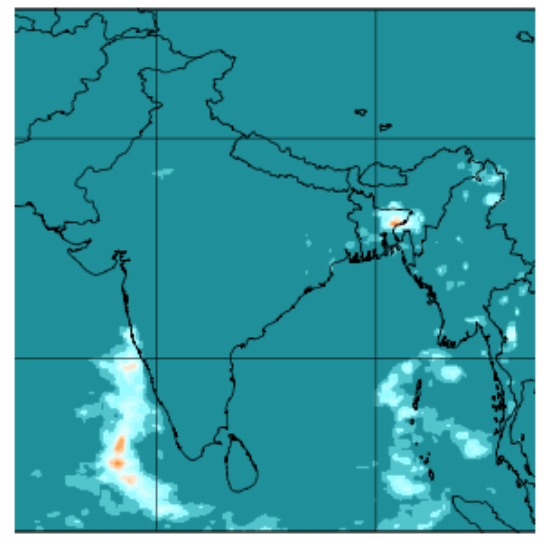

Daily accumulated precipitation (combined microwave-IR) estimate with gauge calibration over land ( $\mathrm{mm}$ )

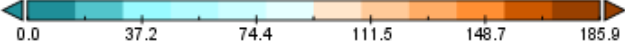

Figure 9:TRMM observation of precipitation during Mora cyclone 


\subsection{Prediction of temperature using Back Propagation ANN in both non cyclonic and cyclonic situation:}

Development and growth of cyclonic situation are depending on background temperature, humidity and wind circulation pattern. One of the important but easily measurable parameter is temperature. In this exercise back propagation method is adopted for assessing the reliability of this model in forcasting temperature during cyclonic situation.

Back propagation is a method used in artificial neural networks to calculate the error contribution of each neuron after a batch of data is processed. This is used by an enveloping optimization algorithm to adjust the weight of each neuron, completing the learning process for that case. There are two phases in back-propagation algorithm in its learning cycle, first the input patterns propagate through the network and other cycle to adapt the output by changing the weights in the network. Back propagation is a general purpose learning algorithm. It is not only powerful but also expensive in terms of computational requirements for training. It requires a dataset of desired output for many inputs, making up the training set. It is more useful for feed-forward networks. The back propagation is a gradient descent method. This method adjusts the weights according to the error function. The network weights are moved along the negative of the gradient of the performance function. The term back propagation refers to the manner in which the gradient is computed for nonlinear multilayer networks.

The algorithm repeats a two phase cycle, propagation and weight update. When an input vector is presented to the network, it is propagated forward through the network, layer by layer, until it reaches the output layer. The output of the network is then compared to the desired output, using a loss function, and an error value is calculated for each of the neurons in the output layer. The error values are then propagated backwards, starting from the output, until each neuron has an associated error value which roughly represents its contribution to the original output.

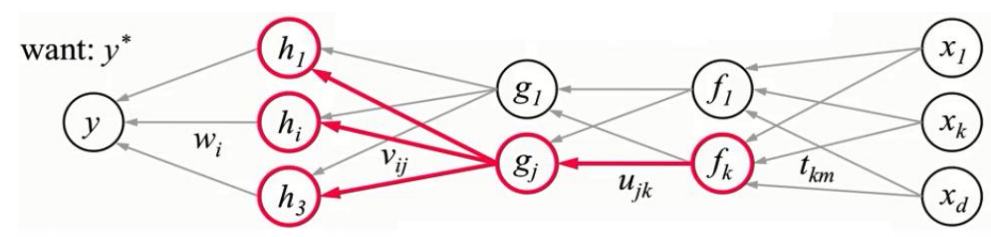

Figure 10: Back propagation method 
Figure 10 shows the back propagation method

I. Receive new observation $\mathrm{x}=\left[\mathrm{x}_{1} \ldots \mathrm{x}_{\mathrm{d}}\right]$ and target $y^{*}$

II. Feed forward: for each unit $\mathrm{g}_{\mathrm{j}}$ in each layer $1 \ldots \ldots$. L. compute $g_{j}$ based on units $f_{k}$ from previous layer:

III. Get prediction $y$ and error $\left(y-y^{*}\right) \quad g_{j}=\sigma\left(u_{j o}+\sum_{k} u_{j k} f_{k}\right)$

IV. Back propagate error: for each unit $g_{j}$ in each layer L....1

a. Compute error on $g_{j} \quad \frac{\partial E}{\partial g_{j}}=\sum \sigma^{\prime}\left(h_{i}\right) v_{i j} \frac{\partial E}{\partial h_{i}}$

b. 1. Compute error on $u_{j k} \quad u_{j k} \leftarrow u_{j k}-\eta \frac{\partial E}{\partial u_{j k}}$

2. Update the weight

$$
\frac{\partial E}{\partial u_{j k}}=\frac{\partial E}{\partial g_{j}} \sigma^{\prime}\left(g_{j}\right) f_{k}
$$

Several works has been done using back propagation neural network. Temperature forecasting is important because they are used to protect life and property [Devi et al., 2012]. Possibility of predicting average summer-monsoon rainfall over India has been analyzed through Artificial Neural Network models [Surajit Chattopadhyay, 2006].

A back propagation artificial neural network should have at least three layers- an input layer, a hidden layer, and an output layer. Number of hidden layers and number of neurons is to be select appropriately in each of them for better experiment performance. This paper proposes a new technique of weather forecasting by using back propagation ANN. The rainfall and temperature data are taken from weather underground for Guwahati region. For this purpose data are trained by Levebberg-Marquardt back propagation algorithm. This is the fastest method among other weather forecasting methods. As there are many back propagation algorithm but among them Levenberg BP has better learning rate. Figure 11 shows ANN model with the hidden layers and output layers. In one complete cycle of the training process, a set of input data of maximum temperature is presented to the input node [Kumar Abhisheka et. al.2012].

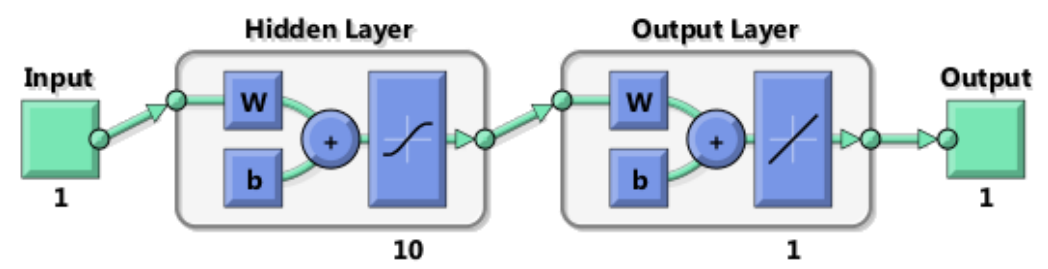

Figure 11: ANN model with ten hidden layers and output layer 
We are taking 24 hour temperature data at Guwahati City to predict the temperature prior and during the Mora cyclone. Figure 12 shows observed and the ANN predicted temperature in quiet and non cyclonic situation taking May 2 as the initial condition. The predicted output is for May $5^{\text {th }}$ as shown in Figure 12, for the entite day. The overall temprature prediction trend though synchronizes with the observational data, model evaluated temptature shows over and underestimation by $10 \%-15 \%$.

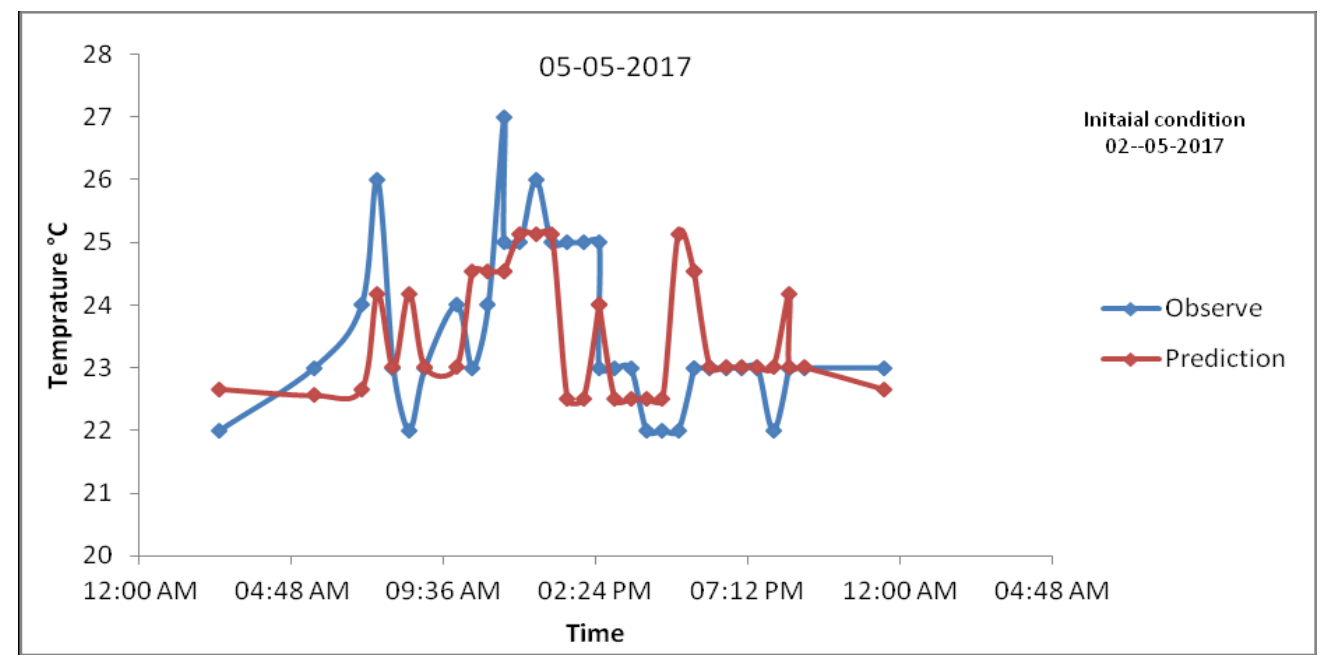

Figure 12: Prediction of temperature by back propagation neural network at no cyclonic situation with initial condition on May 2

Next we present another case study for a normal situation by taking initial condition of May 5 for day-2 prediction of temperature. The results shown in the Figure 13 also indicate similar conclusion as obtained for the case 1 above, where one can note that overall synchronisation of predicated temperature trend is similar to that observed one but model predicted output underestimates the actual temprarutre value by $10 \%$ to $15 \%$. 


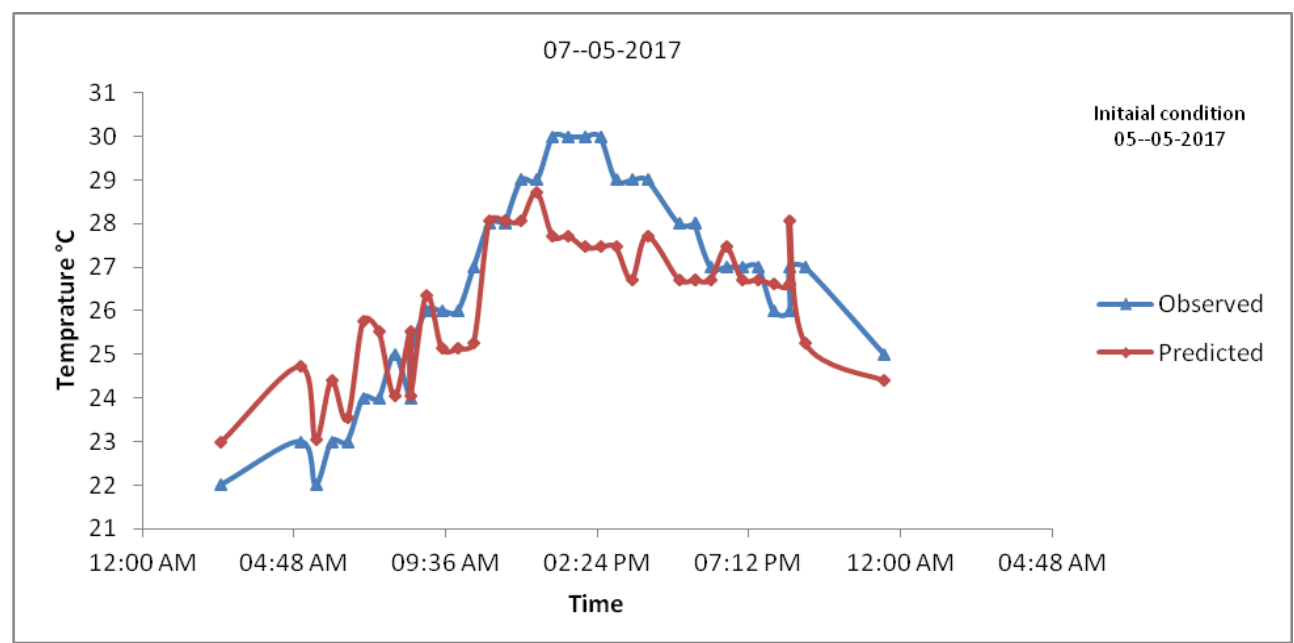

Figure13: Prediction of temperature by back propagation neural network where there is no cyclonc situation

As a final test of the model, the temperatue profiles during the growth (May 29-2017) and decay phases (May 31-2017) of Mora cyclone have been estimated with initial conditions of May 27 and May 29 respectively, as displayed in Figures 14 (a, b). It is clearly seen from the figures that prediction of temperature during the cyclone using this back propagation technique provides a better relatively with lower errors of 9\%-10\% and also that the undulating structures in observed temprearture profile could be well detected by the model.

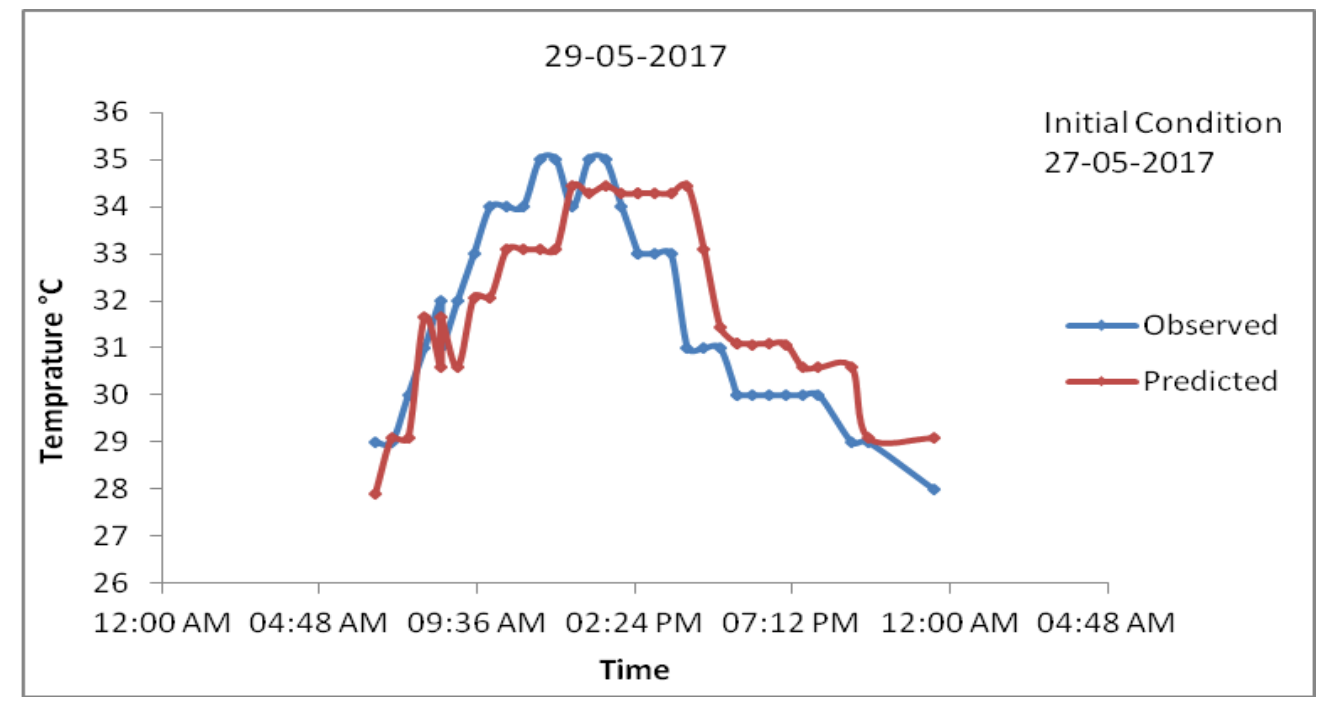

(a) 


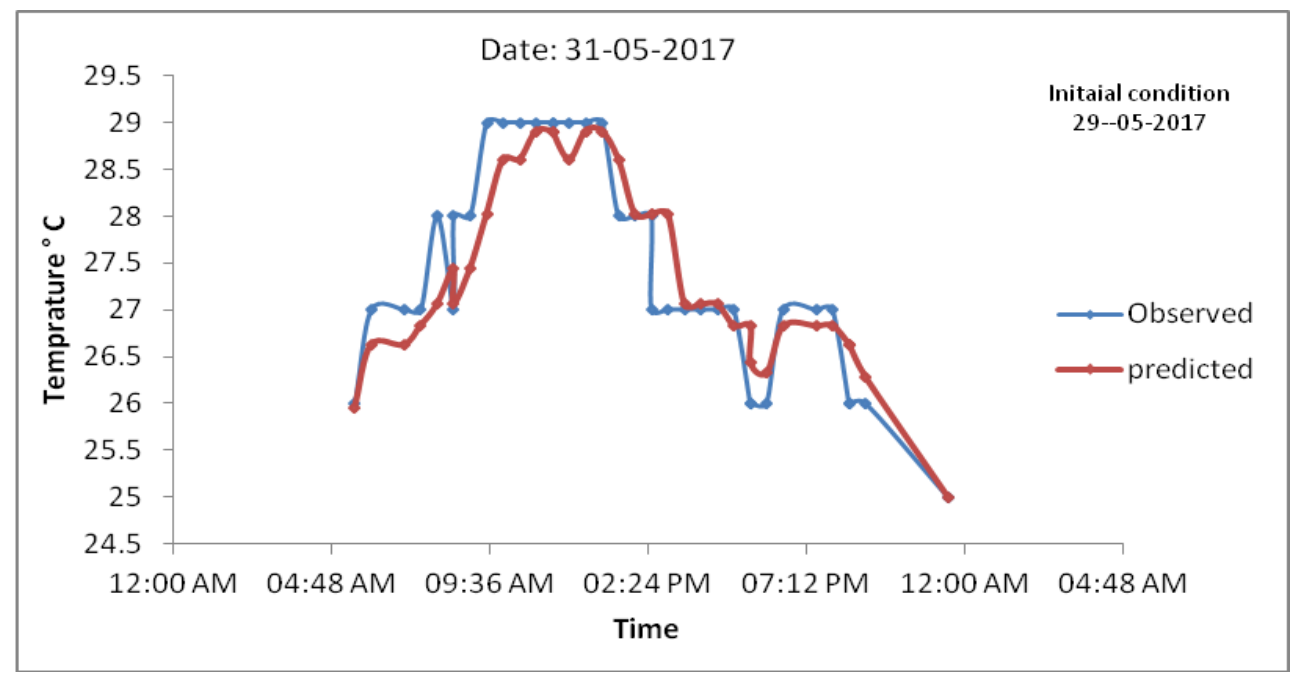

(b)

Figure 14: $(\mathrm{a}, \mathrm{b})$ Prediction of temperature by back propagation neural network when the Mora cyclone generated over BoB

As a further check to our result, the VARSHA predicated temperature data both for non cyclonic situation and during growth / decay periods of Mora cyclone are evaluated and presented in Figure 15. The days are so selected to enable us to examine the results obtained by VARSHA with the above case studies. Figures 15 (a) and (b) show that average temperatures over Guwahti on May 5 and May 7 (Day3) as predicted by VARSHA are $27^{\circ} \mathrm{C}$ and $25^{\circ} \mathrm{C}$ respectively, a difference of $8 \%$ obtained by the ANN model. Such errors are reduced to 5\% when VARSH predicted output (Figure 15 c, d) for May 29 and 31 are presented. Further, the VARSHA output shows gradual increase of sea surface temperature over BoB with the growth of the cyclone Mora.

As a future projection to this work it is planned to adopt an ANN model with induction of aurographic code for improving the reliability. 


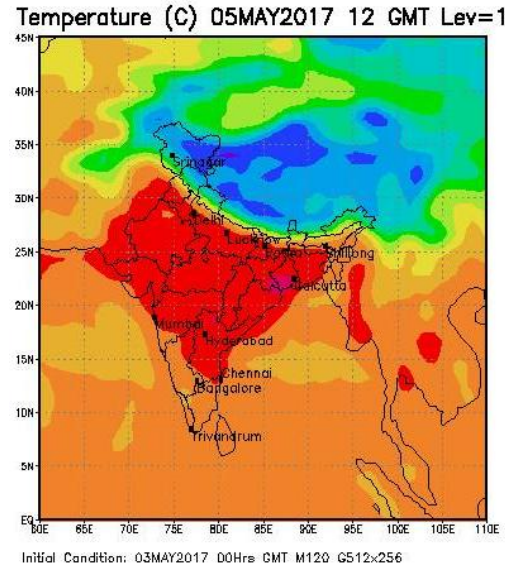

(a)

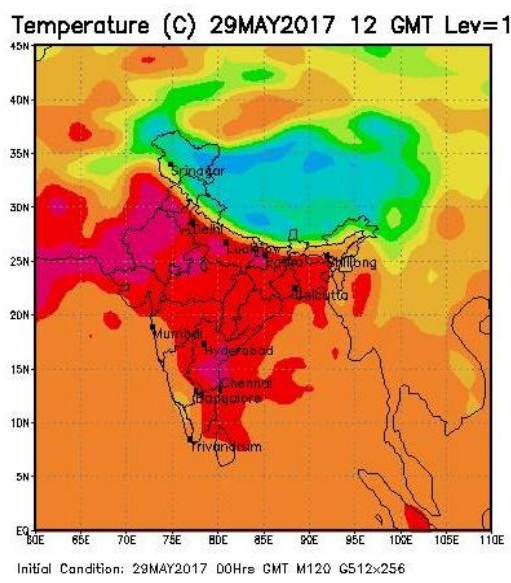

(b)

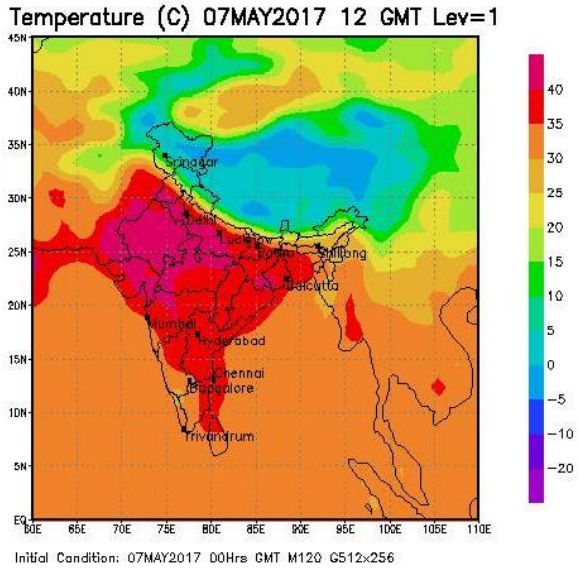

(b)

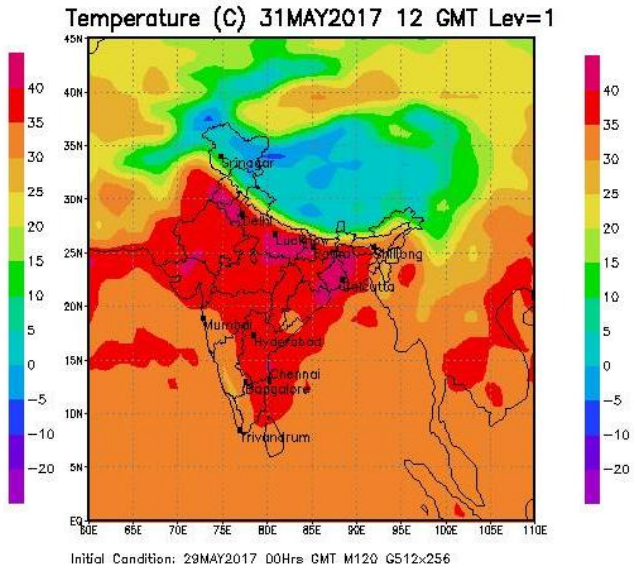

(d)

Figure 15: Growth of temperature during the cyclone Mora

\section{Conclusion}

In this paper, we use numerical model VARSHA to predict the cyclonic track and to study the modifications in temperature and precipitation caused by cyclonic situation over Guwahti. The realibility of model prediction in cyclonic track and also in precipitation over NE are well satisfied with observation data. The back propagation artificial neural network used for predicting the temperature during normal and the cyclonic situation generated over BoB shows an error of $10 \%$ to $15 \%$ for normal sitiation which decreases to $9 \%$ to $10 \%$ on cyclonic sitition. Further ANN model output when compared with VARSHA predicted tempearure, the observed error of $5 \%$ during cyclonic situation indicate reliability of the 
adaptation model to estimate temperature induced by cyclonic situation at the BoB along with the measurements of Sea tempearure modification. Back propagation neural network can be used as an alternative way of traditional meteorological approaches to temperature forecasting.

\section{Reference}

Kumar A, Singha M.P., Saswata G, Abhishek A, Weather forecasting model using Artificial Neural Network, Elsevier Ltd. Selection and/or peer-review under responsibility of C3IT Procedia Technology 4 pp. $311-318,2012$.

Baboo S. S and Shereef. I.K, An Efficient Weather Forecasting System using Artificial Neural Network, International Journal of Environmental Science and Development, Vol. 1, No. 4, ISSN: 2010-0264 pp. 321-326, October 2010.

Baboo S. S and Shereef. I.K, An Efficient Temperature Prediction System using BPN Neural Network, International Journal of Environmental Science and Development, Vol.2, No.1, ISSN: 2010-0264 pp. 4954, February 2011.

Sinha U N, Sarasamma V R, Rajalakshmy S, Subramanian K R, Bharadwaj P V R, Chandrashekar C S, Venkatesh T N, Sunder R, Basu B K, Gadgil S and Raju A, Monsoon Forecasting on Parallel Computers, Current Science, 67, pp. 178-184, 1994.

\section{https://en.wikipedia.org/wiki/Backpropagation}

Kumar k.V., Reddy B. M., Nayak N.R. Devi J., Reddy B. S P, ANN Approach for Weather, Predictionusing Back Propagation, International Journal of Engineering Trends and TechnologyVolume3 Issue1, pp. 19-23, 2012

Chattopadhyay S, 2006, Multilayered feed forward Artificial Neural Network model to predict the average summer-monsoon rainfall in India, pp. 1- 20

Godfrey j. S., 1998, et al., Coupled Ocean-Atmosphere Response Experiment (COARE): An interim report. J. Geophys. Res., 103, 14,395,

Joyce, R. J., Janowiak, J. E. , Arkin, P. A., and Xie, P., 2004, CMORPH: A method that produces global precipitation estimates from passive microwave and infrared data at high spatial and temporal resolution. J. Hydrometeor, 5, pp.487-503. 
Dvorak, V.F., 1975, Tropical cyclone intensity analysis and forecasting from satellite imagery. Mon. Wea. Rev., 103, pp. 420-430.

Englehart, P. J., and Douglas, A. V., 2001, The role of eastern North Pacific tropical storms in the rainfall climatology of western Mexico. Int. Journal of Climatology, 21, pp.1357-1370.

Amorocho, Jaime. and $\mathrm{Wu}$, Baolin., 1977, Mathematical models for the simulation of cyclonic storm sequences and precipitation fields. Journal of Hydrology, 32, pp.329-345.

Stumpf, G. J., Marzban, C., and Rasmussen, E., 1995, The new NSSL mesocyclone detection algorithm: A paradigm shift in the understanding of storm-scale circulation detection.27th Conference on Radar Meteorology, 6A.3, pp. 208-210.

Pu, Z., Tao, W. K., Braun, S., Simpson, J., Jia, Y., Halverson, J., Olson, W., and Hou, A. , 2002, The impact of TRMM data on mesoscale numerical simulation of Super typhoon Paka. Mon. Wea. Rev., 130, pp. 2448-2458.

Chen, S. S., Knaff, J. A.., and Marks, F. D. JR., 2006, Effects of vertical wind shear and storm motion on tropical cyclone rainfall asymmetries deduced from TRMM. Mon. Wea. Rev., 134, pp. 3190-3208.

Lau, William K. M., and Zhou, Y. P., 2012, Observed recent trends in tropical cyclone rainfall over the North Atlantic and the North Pacific. Journal of Geophysical Research, 117, D03104, 13 PP., doi: 10.1029/2011JD016510.

Gautam, R., Singh, R. P., and Kafatos, M., 2005, Changes in ocean properties associated with Hurricane Isabel. International Journal of Remote Sensing, 26, 3 PP. 643-649.

Gautam, R., Cervone, G., Singh, R. P., and Kafatos, M., 2005, Characteristics of Meteorological Parameters Associated with Hurricane. Geophysical Res. Letters, 32, L04801, DOI: 10.1029/2004GL021559

Kotal, S. D., Bhattacharya, S. K., Das, A. K., Sharma, A. S., and Bhowmik, S. K., NWP report on Cyclonic storm 'MAHASEN'over the Bay of Bengal

Devi, M, Kalita, S., Das S., Goswami, H., \& Barbara, A., 2013, Model prediction of cyclonic tracks over Bay of Bengal and resultant precipitation in the north-east region. DOI: 10.1080/19475705.2013.775186

Devi, C. J., Reddy B. S. P., Kumar, K. V., Reddy, B. M., Nayak, N. R., 2012 ANN Approach for Weather Prediction using Back Propagation. IJETT. Vol-3 iss-2, ISSN: 2231-5381 